\title{
Pengaruh Temperatur Terhadap Degradasi Pigmen Tomat dalam Beberapa Jenis Minyak Nabati Komersial
}

\section{Temperature Effect Toward Degradation of Tomato Pigment in Commercial Vegetable Oils}

\author{
Yoga Aji Handoko ${ }^{1 *)}$ dan Indriatmoko ${ }^{2)}$ \\ ${ }^{1}$ Fakultas Pertanian dan Bisnis, Universitas Kristen Satya Wacana \\ ${ }^{2}$ Ma Chung Research Center for Photoshyntetic Pigments, Universitas Ma Chung \\ Jl. Diponegoro No. 52-60, Salatiga, Jawa Tengah 50711 \\ e-mail: yoga.handoko@staff.uksw.edu
}

\begin{abstract}
The study of vegetable oils fortified with crude extract of carotenoid pigments from tomato that contains lycopene as dominant antioxidant compounds becomes an interesting research to be done. The aim of this research is testing the stability of the pigment of tomatoes extracts in the vegetable oil treated on some temperature levels. Spectroscopy method is used to measure the respond of pigment stability in fortified vegetables oils which treated by temperature from $25^{\circ} \mathrm{C}$ to $70^{\circ} \mathrm{C}$. Before the measurement is done by a spectrophotometer which connected to the thermostat, as much as $1 \mathrm{mg}$ of extract pigment of tomatoes in crystal form was weighed for per sampel, then dissolved into $10 \mathrm{ml}$ palm oil, coconut oil, sunflower seed oil, and canola oil separately. The results showed that the temperature treatment causes the value of the optical absorption decreased, which means that the pigment molecules experienced instability. The amount of impairment of the optical absorption with temperature treatment from $25^{\circ} \mathrm{C}$ to $70^{\circ} \mathrm{C}$ at a wavelength of $482 \mathrm{~nm}$, respectively, are: palm oil $(A b s=0.201)$; coconut oil $(A b s=0.213)$, sunflower oil $(A b s=0.232)$; and canola oil $(A b s=0.260)$. Decreasing value of absorbance $(A b s)$ also indicates the lycopene degradation that formed the derivatives molecule of this pigment.
\end{abstract}

Keywords: fortification, lycopene, vegetable oil, temperature, tomato

Diterima: 5 Juli 2016, disetujui 6 September 2016

\section{PENDAHULUAN}

Fortifikasi pangan merupakan salah satu strategi Pemerintah Indonesia dalam menanggulangi kekurangan mikronutrien penting yang diperlukan oleh masyarakat. Beberapa makanan yang difortifikasi (diperkaya) dengan garam yodium telah mulai sejak tahun 1982 dan fortifikasi tepung dengan penambahan zat besi, asam folat, vitamin B1 dan vitamin B2 merupakan proyek besar pada tahun 1997 (Soekirman, 2011). Selain itu, Indonesia juga memiliki tantangan besar dalam pemenuhan ketercukupan vitamin A maupun bahan pangan fungsional yang kaya antioksidan (Soekirman, 2011 dan Hariyadi, 2011). Hal ini mengingat bahwa dalam kurun waktu 25 tahun terakhir, kasus-kasus penyakit yang terkait dengan kekurangan vitamin A, kardiometabolik, maupun kanker semakin meningkat (Hariyadi, 2011 dan Mu'nisa, 2012). Jumlah penduduk yang besar, rendahnya tingkat pendidikan, keterbatasan ekonomi, serta penghalang geografis membuat upaya pemerintah dalam mengedukasi, mendistribusikan dan mencukupi kebutuhan sumber-sumber pangan yang berkualitas yang mengandung senyawa antiosidan tinggi serta vitamin A serta 

Handoko, Y.A dan Indriatmoko : Pengaruh Temperatur Terhadap Degradasi Pigmen Tomat ...

tidaklah mudah. Meskipun sumber pangan yang berkualitas tersebut sesungguhnya tersedia melimpah, namun masyarakat belum mengeksplorasi, mengolah, memanfaatkannnya secara optimal.

Minyak nabati merupakan salah satu dari sembilan bahan pokok yang dikonsumsi oleh kebanyakan orang Indonesia hampir setiap hari. Beberapa jenis minyak sayur yang dikonsumsi oleh masyarakat Indonesia, pada umumnya adalah minyak sawit dan minyak kelapa; serta minyak jagung, minyak kedelai, dan minyak biji bunga matahari, dan minyak canola dalam jumlah terbatas. Besarnya jumlah konsumsi minyak menjadi langkah strategis bagi pemerintah untuk menerapkan kebijakan fortifikasi minyak sayur dalam upaya untuk mengatasi dan menekan penyakit degeneratif. Sejak tahun 2007, studi pengembangan minyak nabati diperkaya dengan vitamin A dan antioksidan telah diinisasi (Soekirman, 2011 dan Hariyadi, 2011). Namun demikian, dari perkembangan informasi; keinginan pemerintah untuk melaksanakan fortifikasi wajib pada produk minyak yang ditargetkan dimulai tahun 2013 tampaknya belum terealisasi secara optimal. Untuk itu, studi fortifikasi pangan fungsional yang kaya vitamin dan antioksidan dengan memanfaatkan ekstrak alami dari berbagai sumber makanan seperti buah-buahan masih perlu terus digali dan dikembangkan. Berdasarkan fakta tersebut, studi minyak nabati yang diperkaya dengan ekstrak kasar pigmen karotenoid dari tomat yang mengandung likopen sebagai senyawa antioksidan yang dominan menjadi penelitian yang menarik untuk dilakukan. Penelitian ini bertujuan menguji stabilitas ekstrak pigmen tomat dalam minyak nabati dengan perlakuan beberapa tingkatan temperatur.

\section{METODE}

Penelitian ini dilakukan di Laboratorium Pigmen, Ma Chung Research Center for Photosynthetic Pigments, Universitas Ma Chung, Malang pada bulan Oktober 2015 s.d. Februari 2016. Bahan yang digunakan adalah ekstrak pigmen tomat yang mengandung pigmen likopen, minyak sawit, minyak kelapa, minyak bunga matahari, dan minyak canola. Peralatan utama yang digunakan meliputi spektrofotometer UVVIS Shimadzu UV-1700 Pharmaspec diintegrasikan dengan thermostat Eyela NTT SB-11.

Preparasi sampel dilakukan tahapan sebagai berikut. Sebanyak $1 \mathrm{mg}$ ekstrak pigmen tomat dalam bentuk kristal ditimbang dan dilarutkan secara terpisah dalam $10 \mathrm{ml}$ berbagai minyak nabati komersial, diantaranya: minyak sawit, minyak kelapa, minyak biji bunga matahari, dan minyak canola. Selanjutnya setiap sampel dihomogenisasi dengan vortek selama \pm 1 menit. Selanjutnya, serapan optik pigmen tomat sebagai Qy dari masing-masing sampel disekrining dan diukur pada panjang gelombang $(\lambda)$ dari $300 \mathrm{~nm}$ sampai $800 \mathrm{~nm}$. Kemudian, sampel siap diuji stabilitas pigmennya.

Pengujian degradasi pigmen tomat yang didominasi likopen melalui perlakuan temperatur (uji termodegradasi) dilakukan setelah pigmen tomat dilarutkan dalam berbagai minyak nabati komersial, secara terpisah (sesuai dengan preparasi sampel diatas). Termodegradasi dilakukan dengan meletakan sampel ke dalam spektrofotometer UV-VIS yang terintegrasi dengan thermostat melalui perlakuan tingkatan suhu mulai dari $25^{\circ} \mathrm{C}$ sampai dengan $70{ }^{\circ} \mathrm{C}$. Selama perlakuan, kuvet yang bersisi sampel di dalam spektrofotometer ditutup. Nilai absorbansi dari hasil pengukuran pada masing-masing sampel yang ditampilkan melalui profil spectra dicatat untuk dianalisis lebih lanjut.

Analisis data meliputi profil kelarutan ekstrak pigmen tomat di berbagai minyak nabati dan profil perubahan pola spektral berdasarkan nilai absorbansi selama perlakuan temperatur pada tiap-tiap sampel. Data diolah dengan menggunakan Program Origin 6.1. serta diintepretasikan secara deskriptif.

\section{HASIL DAN PEMBAHASAN}

Hasil penelitian menunjukkan bahwa ekstrak pigmen tomat dapat larut dalam berbagai minyak nabati, minyak sawit, minyak kelapa, minyak biji bunga matahari, dan minyak canola (Gambar 1). Pengukuran nilai 


\section{Jurnal Penelitian Pertanian Terapan}

absorbansi menunjukkan bahwa pola spektrum didominasi oleh profil likopen dengan puncak serapan pada panjang gelombang $457,482,513 \mathrm{~nm}^{3}$.

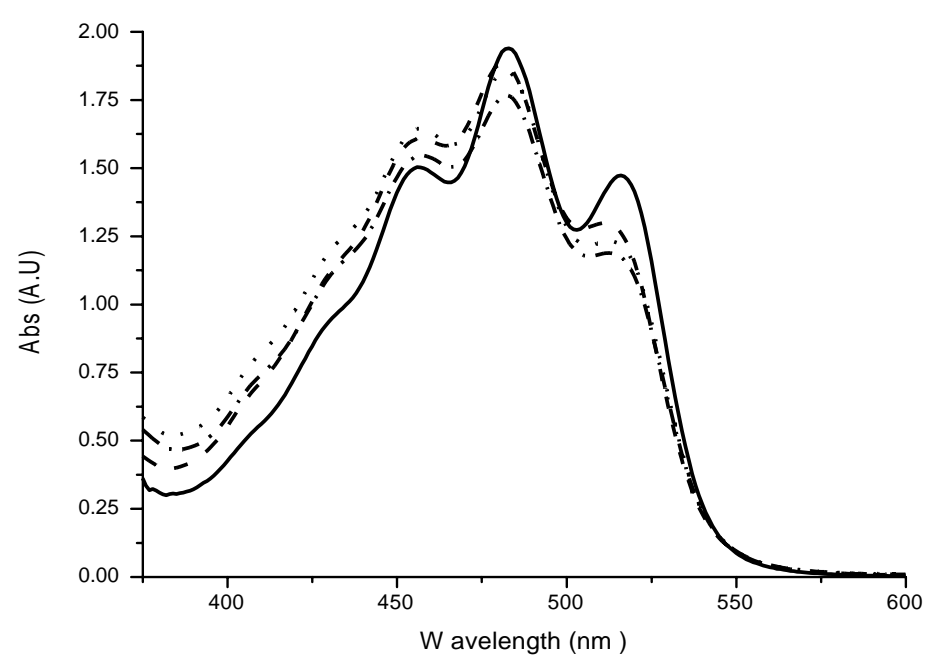

Gambar 1. Kelarutan Ekstrak Pigmen Tomat dalam Beberapa Minyak Nabati minyak sawit ( ); minyak kelapa( . . . ); minyak canola ( ........ ); minyak biji b. matahari ( .... ).

Berdasarkan Gambar 1 tersebut, ekstrak pigmen tomat memiliki kelarutan yang lebih baik di dalam minyak sawit. Kelarutan pigmen tomat pada minyak sawit di tingkat spektra teratas karena minyak sawit memiliki kandungan asam lemak total yang lebih tinggi dibandingkan minyak kelapa, minyak bunga matahari, dan minyak canola. Asam lemak ini memiliki keterkaitan dengan tingkat polaritas dan ikatan kompleks pigmen karotenoid (Esteban B, et al., 2012 dan Pambou-Tobi NP, et al., 2010). Tabel 1 menjelaskan beberapa puncak serapan optik pigmen tomat dari masing-masing sampel.

Tabel 1. Puncak Serapan Optik Ekstrak Pigmen Tomat pada Bebeapa Minyak Nabati Komersial

\begin{tabular}{ccccc}
\hline \multirow{2}{*}{$\lambda(\mathrm{nm})$} & \multicolumn{4}{c}{ Abs (A.U.) } \\
\cline { 2 - 5 } & minyak sawit & minyak kelapa & minyak canola & minyak biji b. Matahari \\
\hline 457 & 1.504 & 1.610 & 1.645 & 1.547 \\
482 & 1.940 & 1.886 & 1.860 & 1.768 \\
513 & 1.474 & 1.300 & 1.232 & 1.188 \\
\hline
\end{tabular}

Suhu merupakan salah satu faktor yang mempengaruhi stabilitas pigmen, seperti likopen. Likopen merupakan pigmen yang stabil pada atau di bawah suhu kamar (Abbeddou, et al., 2013). Perlakuan suhu pada ekstrak pigmen tomat menunjukkan respon stabilitas yang berbeda-beda pada masing-masing sampel. Penurunan nilai absorbansi menunjukkan bahwa pigmen terdegradasi (Gambar 2). Hal ini juga menunjukkan peregangan ikatan kompleks antara minyak dengan degradasi molekul pigmen alami ketika suhu dinaikkan secara bertahap mulai $25{ }^{\circ} \mathrm{C}, 40{ }^{\circ} \mathrm{C}, 55^{\circ} \mathrm{C}$, hingga $70{ }^{\circ} \mathrm{C}$. Peningkatan suhu mempengaruhi viskositas dan komposisi senyawa polar (Fasina OO, Z. Colley. 2008). Demikian juga, suhu yang lebih tinggi membuat viskositas minyak menurun (Fasina OO, Z. Colley. 2008; Keshvadi A, et al., 2011; dan Esteban B, et al., 2012), polaritas meningkat (Pambou-Tobi NP, et al., 2010), serta kemungkinan mengalami oksidasi (Abbeddou, et al., 2013). Produk degradasi karotenoid dapat berkontribusi pada reaksi radikal, tetapi efisiensinya tergantung pada spesies radikal dan struktur produk degradasi yang dihasilkan selama perlakuan temperature (Abbeddou, et al., 2013). Produk degradasi pigmen tomat ini memiliki kemungkinan senyawa- 
Handoko, Y.A dan Indriatmoko : Pengaruh Temperatur Terhadap Degradasi Pigmen Tomat ...

senyawa teroksidasi yang dapat menimbulkan efek radikal bebas dan risiko kesehatan (Mesembe OE, et al., 2004).

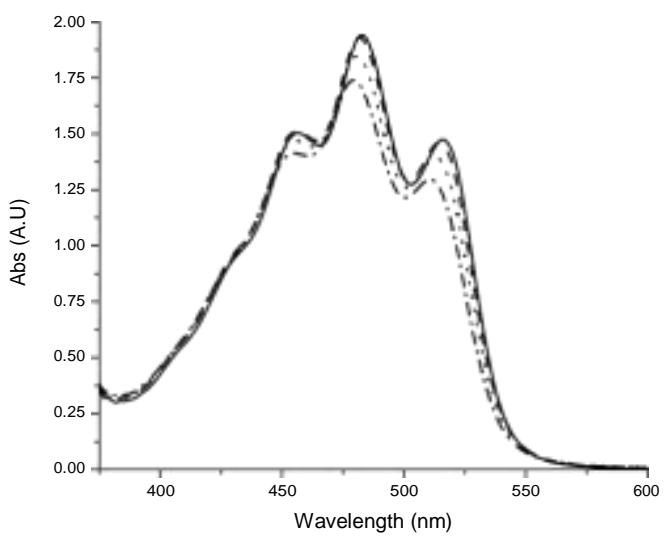

(A)

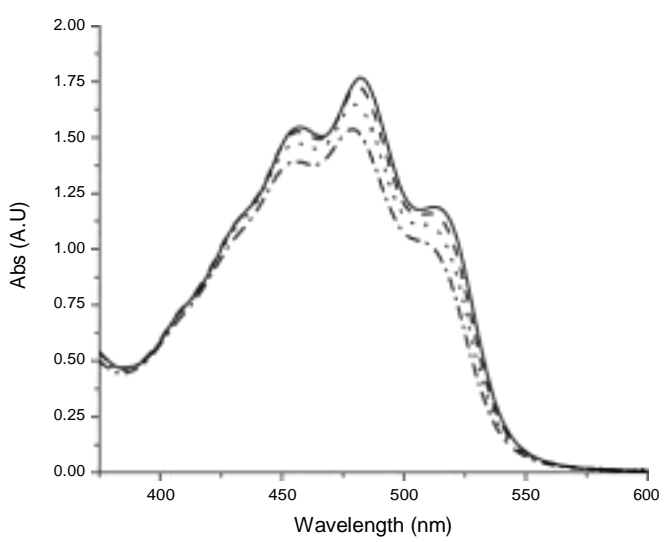

(C)

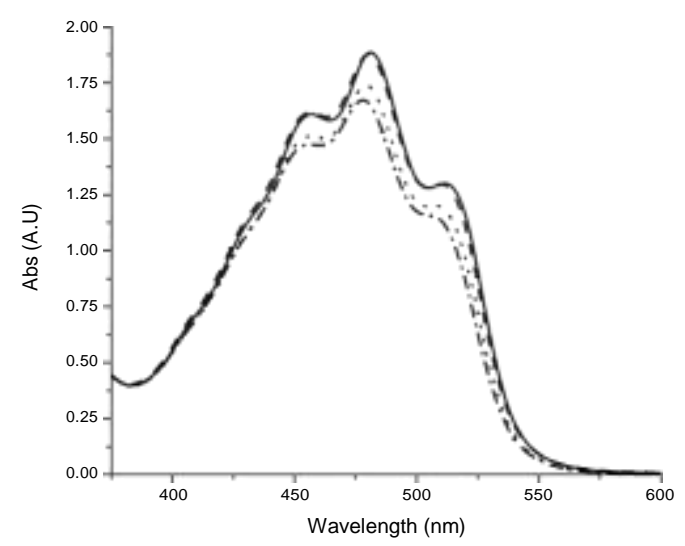

(B)

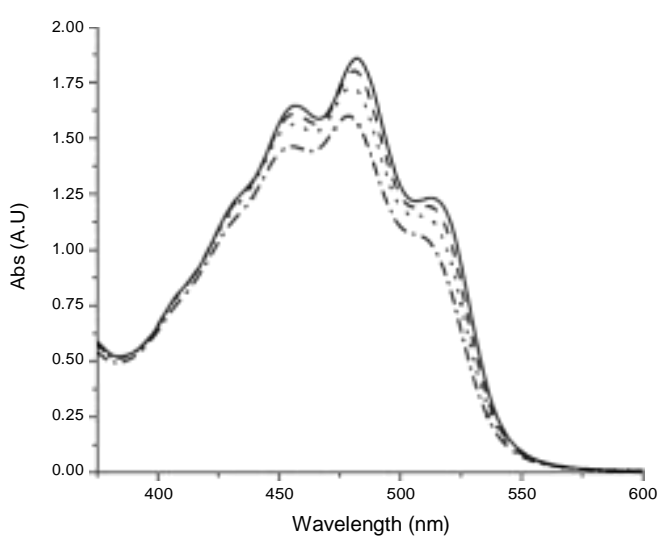

(D)

Gambar 2. Pola Degradasi Pigmen Tomat pada minyak sawit (A), minyak kelapa (B), minyak biji b. matahari (C), dan minyak canola (D) dengan perlakuan temperatur pada suhu $25^{\circ} \mathrm{C}($ )$; 40{ }^{\circ} \mathrm{C}($. . . $) ; 55{ }^{\circ} \mathrm{C}(\ldots \ldots) ; 70$ ${ }^{\circ} \mathrm{C}(\ldots .$.

Perlakuan temperatur yang lebih tinggi menyebabkan pigmen tomat yang didominasi oleh likopen mengalami penurunan konsentrasi. Tabel 2. menunjukkan bahwa minyak canola terdegradasi lebih tinggi dibandingkan dengan minyak bunga matahari, minyak kelapa, dan minyak sawit. Tabel 2. tersebut juga menunjukkan bahwa minyak sawit lebih stabil daripada yang lain. Secara umum, minyak kelapa sawit memiliki kandungan asam lemak total cukup tinggi dibandingkan dengan minyak nabati lainnya.

Table 2. Nilai Degradasi Ekstrak Pigmen Tomat dengan Perlakuan Temperatur

\begin{tabular}{|c|c|c|c|c|c|c|c|c|c|c|c|c|}
\hline \multirow{3}{*}{$\lambda(\mathrm{nm})$} & \multicolumn{12}{|c|}{ Abs (A.U) } \\
\hline & \multicolumn{3}{|c|}{ minyak sawit } & \multicolumn{3}{|c|}{ minyak kelapa } & \multicolumn{3}{|c|}{ minyak biji b.matahari } & \multicolumn{3}{|c|}{ minyak canola } \\
\hline & $25^{\circ} \mathrm{C}$ & $70^{\circ} \mathrm{C}$ & $\Delta^{\circ} \mathrm{C}$ & $25^{\circ} \mathrm{C}$ & $70^{\circ} \mathrm{C}$ & $\Delta^{\circ} \mathrm{C}$ & $25^{\circ} \mathrm{C}$ & $70^{\circ} \mathrm{C}$ & $\Delta^{\circ} \mathrm{C}$ & $25^{\circ} \mathrm{C}$ & $70^{\circ} \mathrm{C}$ & $\Delta^{\circ} \mathrm{C}$ \\
\hline 457 & 1.504 & 1.413 & 0.091 & 1.610 & 1.474 & 0.136 & 1.547 & 1.392 & 0.155 & 1.645 & 1.463 & 0.182 \\
\hline 482 & 1.940 & 1.739 & 0.201 & 1.886 & 1.673 & 0.213 & 1.768 & 1.536 & 0.232 & 1.860 & 1.600 & 0.260 \\
\hline 513 & 1.474 & 1.296 & 0.178 & 1.300 & NA & - & 1.188 & NA & - & 1.232 & NA & - \\
\hline
\end{tabular}




\section{KESIMPULAN DAN SARAN}

Hasil penelitian menunjukkan bahwa perlakuan pada suhu yang semakin tinggi dari semua sampel menyebabkan tingkat penyerapan optik menurun, yang berarti bahwa molekul pigmen alami ketidakstabilan. Jumlah penurunan serapan optik dengan perlakuan temperatur dari $25{ }^{\circ} \mathrm{C}$ ke $70{ }^{\circ} \mathrm{C}$ pada panjang gelombang $482 \mathrm{~nm}$, masing-masing adalah: minyak sawit (Abs $=0,201)$; minyak kelapa (Abs $=0,213)$, minyak bunga matahari $(\mathrm{Abs}=0,232)$; dan minyak canola $(\mathrm{Abs}=0.260)$. Selama penurunan konsentrasi pada ekstrak pigmen tomat, pengujian produk degradasi dengan menggunakan spektrofometer massa perlu dilakukan pada studi selanjutnya. Produk degradasi ini akan menyediakan petunjuk terkait dengan kemungkinan senyawa teroksidasi yang dapat menyebabkan efek radikal bebas.

\section{UCAPAN TERIMA KASIH}

Penulis mengucapkan terima kasih kepada Saudara Monika Nur Utami Prihastyanti dan Saudara Marcellinus A. S. A. atas dukungan dan beberapa diskusi dalam menggunakan dan menganalisis metode spektroskopi. Demikian juga ucapan terima kasih disampaikan kepada Prof. Ferdy Semuel Rondonuwu, $\mathrm{Ph} . \mathrm{D}$. yang memberikan motivasi, arahan, dan koreksi terhadap penulis.

\section{DAFTAR PUSTAKA}

Abbeddou, S, C. Petrakis, A. Pe'rez-Ga'lvez, P. Kefalas, D. Hornero-Me'ndez. 2013. Effect of simulated thermo-degradation on the carotenoids, tocopherols and antioxidant properties of tomato and paprika oleoresins. J Am Oil Chem Soc 90:1697-1703.

Esteban B, JR. Riba, G. Baquero, A. Rius, R. Puig. 2012. Temperature dependence of density and viscosity of vegetable oils. Biomass and Bioenergy 42:164-171.

Fasina OO, Z. Colley. 2008. Viscosity and specific heat of vegetable oils as a function of temperature: $35^{\circ} \mathrm{C}$ to $180^{\circ} \mathrm{C}$. International Journal of Food Properties 11:738-746.

Hariyadi, P. 2011. Teknologi Fortifikasi Vitamin A pada Minyak Sawit. Direktorat Industri Makanan, Hasil Laut, dan Perikanan. Kementerian Perindustrian RI. 16 Maret 2011. Jakarta.

Keshvadi A, JB. Endan, H. Harun, D. Ahmad, F. Saleena. 2011. The effect of high temperature on viscosity of palm oil during the ripening process of fresh fruits. International Journal of Scientific \& Engineering Research 2(6):1-7.

Mesembe OE, I. Ibanga, EE. Osim. 2004. The effects of fresh and thermoxidized palm oil diets on some haematological indices in the rat. Nigerian Journal of Physiological Sciences 19(1-2):86-91.

Mu'nisa, A. 2012. Analisis kadar likopen dan uji aktivitas antioksidan pada tomat asal Sulaesi Selatan. $J$. Bionature 13(1): 62-66.

Pambou-Tobi NP, JM. Nzikou, L. Matos, et al. 2010. Comparative study of stability measurements for two frying oils: soybean oil and refined palm oil. Adv J Food Sci Technol 2(1):22-27.

Soekirman. 2011. Fortifikasi. http://www.kfindonesia.org/index.php.2011. [diakses August 14 ${ }^{\text {th }}, 2015$ ]. 